\title{
The Erasure of Race and Racism
}

\author{
Andrew Pilkington \\ School of Social Sciences, University of Northampton, Northampton, UK \\ Email: Andrew.pilkington@northampton.ac.uk
}

Received March 14 ${ }^{\text {th }}$ 2013; revised April 15 ${ }^{\text {th }}$, 2013; accepted April 22 $2^{\text {nd }}, 2013$

\begin{abstract}
Copyright (C) 2013 Andrew Pilkington. This is an open access article distributed under the Creative Commons Attribution License, which permits unrestricted use, distribution, and reproduction in any medium, provided the original work is properly cited.
\end{abstract}

\begin{abstract}
With the advent in the UK of a new Labour government in 1997 and the publication of the Macpherson report in 1999, public debate over race and racism was reactivated after a long period when such concerns had remained dormant. In this article, I shall draw upon an ethnographic study of one university in the UK over a ten year period (Pilkington, 2011a). Here I shall focus on the early part of that period, predominantly 1999-2003 when arguably issues relating to race and racism were at their height. I examine how Midshire University responded in turn to the Commission for Racial Equality's (CRE's) leadership challenge; the government's strategies for higher education relating to widening participation and equal opportunities; and the race relations legislation. The story is not a happy one, with the institution constantly subsuming race under a more general agenda and in the process failing to address the specificities of race. Midshire University is unlikely to be the only university to do this. Universities in UK are typically characterised by the "sheer weight of whiteness" which blinds senior managers and academics to racial inequalities in their midst.
\end{abstract}

Keywords: Race; Racism; Equality; Diversity; Higher Education; Widening Participation

\section{The Leadership Challenge}

The CRE issued its leadership challenge to higher education institutions (HEIs) in June 1997. The Committee of Vice Chancellors and Principals (CVCP) was an early signatory and thus committed Midshire University, along with other HEIs, to give consideration to the issue of race equality. At Midshire University, the first indication that the issue was being addressed was in February 1998, with a paper from the Vice Chancellor to the university's equal opportunities working group (EOWG) outlining the challenge and requesting suggestions as to how the university might respond.

A subgroup of the EOWG met to consider proposals, with the equal opportunities coordinator eventually writing back on behalf of the group to the Vice Chancellor with nine recommendations. These comprised nine ethnically targeted initiatives. The initiatives were not at all idiosyncratic but reflected recognised good practice and covered measures relating to ethnic monitoring; target setting; positive action; impact assessment; training; mentoring; special interest groups; and research.

In most cases, the initiatives were already integral parts of the race equality plan, which had been devised between 1992 and 1994, approved subsequently by Senate, and launched as recently as 1996 . That plan only two years later, however, was already languishing in a filing cabinet, forgotten except by a few diehards. At a workshop in April 2000 on institutional racism, only one of the fourteen participants knew about the plan and at a repeat workshop on another campus, only one of the participants knew of it. Even some members of the EOWG were unaware of its existence. The Chair of the group and the equal opportunities coordinator remembered it, but some members had no inkling of its existence and even those who said they knew of the plan were often thinking of something else. Two members of the group whom I interviewed, in 2000 and 2002 respectively, for example, indicated that they did know about the plan, but when asked what they understood by it, referred to more contemporaneous policy statements (the Vice Chancellor's millennium pledge and a proposed new equal opportunities statement). Since the race equality plan was already a dead document in 1998, it is perhaps not surprising that the recommendations put forward to the Vice Chancellor were presented as though they were new ideas.

The Vice Chancellor formed a working group of ten staff and two students to take the leadership challenge forward. The group comprised staff and students whom he knew were committed to equal opportunities. The group held its first meeting in April 1999, two months after the publication of the Macpherson report. The Vice Chancellor reported back to EOWG in October 1999 on the "outcome of its deliberations". He reported that the group saw race as part of a wider set of issues; that he was taking forward the challenge in relation to a millennium statement/pledge and asked the group to devise a resource neutral action plan to promote race equality.

This paper is revealing because it heralds an approach to race that becomes the institutional norm. Race is not specifically addressed but is subsumed under a more general agenda. The Vice Chancellor presents the group's thoughts in the following way: "We did not wish to isolate racial issues from other aspects of intolerance and prejudice. This has led directly to the establishment of a group under my chairmanship to take forward my millennium commitment to tolerance and equality of opportunity. This is not to suggest that we do not support the objectives of CRE; Leadership Challenge and I reaffirm my 
commitment to giving a lead in promoting the principle of racial equality together with the practical action that will make it reality” (Midshire University, 1999b).

When it comes to EOWG's recommendations for "practical action", the Vice Chancellor's response is interesting. The "I" becomes more pronounced and the "we" now refers no longer to the VC's group but to a purportedly consensual institution. After summarising EOWG's recommendations, he writes: "In the light of these consultations, I would wish the Equal Opportunities Group to review these various practical issues and to develop an action plan in relation to the promotion of racial equality at Midshire ... It must be realistic in terms of what hard-pressed colleagues can be expected to undertake, and what the institution can take on board ... There can be no expectation of additional funding to support this. The Working Group must therefore address priorities for racial equality against other Equal Opportunity requirements, particularly in relation to the institution's responsibilities under the Disability legislation" (Midshire University, 1999b).

The EOWG formed a subgroup to devise an action plan, but this did not meet prior to the EOWG meetings either in December 1999 (Midshire University, 1999a) or February 2000 (Midshire University, 2000a). Eventually the equal opportunities coordinator concocted a one page draft plan for the EOWG meeting in June, 2000. The plan was a generic equal opportunities one. Race was only mentioned once and that was in relation to a proposal to "explore the possibility of commissioning a research project to monitor $\mathrm{EO}$, in areas of race, gender and disability". It was agreed to forward the plan to the Senior Executive Team (comprising the Directorate and Deans). The Chair subsequently reported in October 2000 (Midshire University, 2000a) that the Pro Vice Chancellor was taking the recommendations forward. Given the vagueness of the plan, that was effectively the end of any serious action plan to promote race equality emanating from the challenge. The race equality plan approved by Senate in 1996 had not been resurrected. Instead, the recommendations relating to race equality presented to the Vice Chancellor (VC) in 1999 had been thrown back to the EOWG. These in turn had eventually been subsumed into a more general plan and then disappeared from sight.

This is not to say that nothing happened as a result of the CRE's leadership challenge. The Vice Chancellor's group continued to meet and on the surface its deliberations were very productive. It discussed the wording of the VC's millennium pledge and sought to give substance to this pledge in number of ways. These included conducting an EO audit and passing the results to the EOWG for consideration; hosting two events in 2000 relating to racial and sexual discrimination, respectively; and following up these events with workshops on both campuses on race, gender and disability.

The millennium pledge was issued on January 13, 2000 to all staff. It was entitled "Millennium commitment from the Vice Chancellor" and entailed a pledge to uphold certain basic principles: Midshire University commits itself for the millennium to the continuing values and fundamental principles of European Universities. For Midshire University to realise such principles it will:

- Preserve freedom in research and teaching, and recognise that the freedom of the academic community must be available to all members of its community

- Ensure that its students' freedoms are safeguarded and that they enjoy conditions in which they can maximise their educational opportunities

- Regard the mutual exchange of information for the advancement of learning as essential to the steady progress of knowledge. In committing Midshire University to these principles and in pursuit of their implementation, the Vice Chancellor commits the leadership and direction of Midshire University to the principles of academic freedom and of equality of opportunity. In that context, this Millennium Pledge reaffirms the Mission and Equal Opportunities Policy of the institution, with the recognition that

- All discrimination is discrimination

- Equality is due to all

Through its practices, Midshire University will demonstrate an institutional commitment to the equality of opportunity [policy] and to the monitoring of its effectiveness at all levels ... Equality and excellence in higher education are recognised as necessary prerequisites for each other. Hence this commitment reaffirms the University to both the traditions and values of academic freedom and tolerance, and to the ideals and expectations of equality. The realisation and re-evaluation of both is the challenge for Midshire University in the coming millennium' (Midshire University, 2000b).

While the Vice Chancellor's statement was publicised as the "Equal Opportunities Millennium Pledge", the pledge arguably prioritises academic freedom. The first three bullet points concern academic freedom and, in the subsequent sentence, academic freedom is mentioned before equality of opportunity. The statement is as concerned with what the VC considers to be a serious threat to academic freedom from state intervention as equality of opportunity. In an interview with him, this becomes evident: "Government is increasingly interfering in the running of universities. If you look at our funding, more and more is being given for specific purposes, 'ringfencing' activities, so it becomes increasingly difficult to say that we have freedom over how we choose to direct our activities. The 'Millennium Commitment' sets out what I see as the basic principles of European universities; they are not tied to the state; they are free to challenge opinions and to challenge the government and should not be at risk if they do so".

While the millennium statement asserts that the principles of academic freedom and equality of opportunity are compatible and mutually entail each other, there is some recognition in the penultimate sentence that these principles have different roots. There is certainly a tension between them in practice and, as I have argued elsewhere (Pilkington, 2011b), it may take state intervention to stimulate the academy to take race equality seriously.

The statement pledged the university to monitor the effectiveness of its equal opportunities policy and the Vice Chancellor's working group seemingly contributed to fulfilling this pledge by conducting an audit of current practice in January 2000 against a checklist formulated by the VC the previous November. The outcomes of the audit were written up and presented in a paper to the EOWG meeting in February 2000 (Midshire University, 2000a). Although it was entitled an audit, it was not based on an examination of any university documents and entailed no interviews. It differed markedly in this respect from internal audits conducted during 2000 as part of the university's investors in people designation and the external "continuation audit" of the university conducted by the Quality Assurance Agency (QAA). In contrast to these audits, where 
assertions needed to be evidenced, the EO audit comprised on its own admission "the reflections of people around [a] table" (Midshire University, 2000c). It is noteworthy that these reflections made no reference to race.

The discourse was markedly different from that found in audit reports, with constant reference to feelings and unsubstantiated thoughts. Here are some extracts: "Ethos: We felt that this was good compared with many other institutions of which we had knowledge; it seemed that the Mission and the Equal Opportunities Policy were reflected 'down' through the institution ... Language and imagery: We welcome the extent to which the institution had moved on from slavish political correctness ... Staff development and training: Members believed that there were excellent opportunities at Midshire University. Concern was, however, expressed as to the basis for some managers' selection of staff for development opportunities and the extent to which this could be justified in terms of equal opportunities" (Midshire University, 2000c).

The four page report was sent to the EOWG with this preface from the VC: “As its final task my working group ... undertook an 'audit' of our equal opportunities practices. We submit it to the Equal Opportunities Group on behalf of my working group, with the hope and expectation that you will use it as a checklist against which to review the effectiveness of our Equal Opportunities Policies and Practices, and to inform your thinking and advice, regarding the future development and operation of these" (Midshire University, 2000c). The paper was received by the EOWG at its February meeting, where it was decided that the subgroup supposedly developing a race (sic) equality action plan would consider it further. The VC's hope and expectation that it would inform the group's thinking were not fulfilled.

In addition to conducting an audit, the VC's working group sought to give substance to the millennium pledge by hosting two events and following these up with workshops. At the instigation of the equal opportunities coordinator, the university decided to host an exhibition, Anne Frank: A History for Today. The exhibition was launched on 21 March 2000, with Richard Stone, one of the three advisors to Sir William Macpherson on the Stephen Lawrence Inquiry, giving the keynote lecture. The exhibition, which included displays on the Third Reich but also on the life of Stephen Lawrence, lasted till 7 April 2000. In a letter reported to the EOWG at its meeting in June 2000, the VC complimented the equal opportunities coordinator on the launch: "The opening event was a great success ... Many colleagues and Governors who were present spoke to me about how they felt that this had been a very good occasion for Midshire University (MU) in relation to the wider community ... Though I know the purpose of the occasion was not to reflect 'glory' on MU, nevertheless it did, and that in return impacted on the real purpose of the Exhibition" (Midshire University, 2000a). Thus an event "that documented ... racism ... got quickly translated [and] became usable as a measure of good performance" (Ahmed, 2007: p. 599).

The exhibition was followed up with two workshops in April and November, 2000. They were advertised in relation to the question, "Is Midshire University characterised by institutional racism?” Fourteen people attended the first workshop with approximately the same number putting their thoughts in email correspondence. The workshop culminated in a brief report from the equal opportunities coordinator. This provided a summary of the workshop and concluded that the participants from across MU agreed that MU was not as serious as it should be on equal opportunities. The following examples were given to justify the claim that MU does not take equal opportunities seriously:

- The Chair of the EOWG is not a member of the Directorate;

- The EO co-ordinator is only part-time;

- The [Race Equality] Policy document has not been properly monitored;

- There is no systematic monitoring or target setting;

- Monitoring that is done is not used effectively (Midshire University, 2000d).

These comments informed the subsequent nine recommendations which related to leadership and staffing in EO; action planning; review and monitoring; staff development and training; and research. The report was forwarded to EOWG and was received at its meeting in June where "as a way forward the Chairman agreed that [it] be sent to the Vice Chancellor in the first instance for his consideration" (Midshire University, 2000a). At the subsequent meeting of EOWG in October, 2000 it was reported that the "report ... had been received with interest by the Vice Chancellor. A repeat of this workshop would now take place at Field campus” (Midshire University, 2000a). The proposals in the paper had fallen on barren ground. The subsequent workshop, which attracted slightly more participants, culminated in a call for research on institutional racism at Midshire and a reminder to EOWG that there had been no response to the previous workshop's proposals. The silence was resounding.

The leadership challenge led to some activity but it led to little action that made a difference to equal opportunities let alone race equality at Midshire University. The ball was continually passed between the EOWG and the VC. This partly reflected the governance arrangements. The EOWG was an advisory group to the Vice Chancellor. The group included few academics or senior staff and was chaired by a Head of School who had no executive responsibilities for equal opportunities. Decisions were continually deferred and instead proposals were forwarded to the VC and Senior Executive Team (SET) for their consideration. While the VC did devote some time and energy to equal opportunities issues, he was mainly concerned with key principles. He saw strategic issues as the purview of SET and implementation issues as the responsibility of EOWG and the equal opportunities coordinator. SET, however, paid scant attention to equal opportunities during this period and thus received rather than discussed EOWG's minutes, while EOWG did not have the authority effectively to implement equal opportunities policies and the equal opportunities coordinator only held a fractional 0.5 post.

In conversations I had with the VC, Chair of EOWG and the equal opportunities coordinator, I discovered that each of them recognised that the current arrangements were unsatisfactory. The VC referred to the EOWG as "a talking shop where like-minded people don't do anything but just talk sweet nothings to each other"; the Chair acknowledged that "EOWG need[ed] to become more action centred [and] there also need[ed] to be a stronger central steer from the Directorate"; and the equal opportunities coordinator expressed frustration at what she saw as "going through the motions where those whose responsibility it is to lead have just passed it down and passed it along”.

This is not to say that between 1999 and 2000 race issues were completely bypassed. Participation in the national men- 
toring scheme run by the University of East London for minority ethnic students continued; a summary of the Carter et al report (1999) was produced by the equal opportunities coordinator for members of the EOWG; the Anne Frank exhibition was launched with follow up workshops; and a series of recommendations focusing on race equality were forwarded to the VC. Nonetheless, what above all characterises the university's response to the leadership challenge is the way race was subsumed under a more general agenda and any specificities were lost. It is revealing in this context that the item in the EOWG minutes that initially was entitled "Race equality-leadership challenge" later transmogrifies into one entitled, "Millennium commitment to tolerance and equality" (Midshire University, 1999a, 2000a).

\section{Widening Participation}

A concern with access was evident at Midshire University well before widening participation became a national priority. During the 1980s, "access was seen as a means of helping us maintain our market position to recruit students" according to the Director of Widening Participation (WP). It became less significant "towards the end of the 80s when recruiting was easy” and A level points were seen as a performance indicator, but "it's come back on the agenda in the last five years because of government policies about expanding higher education and the realisation that you can't do that effectively unless you widen it”.

Midshire University's first foray with the national agenda on widening participation was in 1998. The university received funding along with a number of local FE colleges and the local education authority (known collectively as the Midshire federation) for a one year research project to produce social and demographic data on Midshire in order to facilitate strategic planning to widen participation in higher education. The final report was produced in January 2000 and informed the subsequent three year project.

This project focused expressly on students from poor socioeconomic backgrounds. A widening participation unit was set up and a progression partnership (with ten schools identified in the earlier pilot project as located in deprived wards and/or with low educational achievement relative to county norms) became the main vehicle for increasing participation from low participation neighbourhoods and lower social classes. An independent evaluation report produced in January 2003 indicated the project was successful and that there was a sound base for the development of a sub-regional Aimhigher: Progression for Partnership. The latter began operating in April 2003 but only a year later in August 2004 transmogrified into Midshire Aimhigher.

It is noticeable that between 1998 and 2003 no reference is made in any of the pertinent documents to race. Successive outreach programmes exclusively focused on social class. It is only with the emergence of Aimhigher in 2004 that any concern with students from minority ethnic communities is manifest. In addition to these partnerships concerned with outreach activities, Midshire University since July 2001 had its own widening participation strategy. The strategy developed in 2001 was expressly concerned with improving the recruitment of specified target groups, notably students from lower social classes, students from low participation neighbourhoods and mature students. In addition, the strategy was concerned with improving retention and progression generally and especially for target groups. An additional set of targets included raising institutional degree profiles and employment outcomes. The strategy document noted that "Midshire University will use the PIs published annually by HEFCE as its key measure of success" (Midshire University, 2001b). Since these take no account of race, the strategy virtually ignored this dimension of inequality, with the institutional widening participation plan for the period from 2001-02 to 2003-04 identifying only one target on race, namely increasing the participation of minority ethnic students on the national mentoring scheme.

The institutional strategy insisted that schools produced their own widening participation plans. An analysis by the Director of Widening Participation of plans in 2001-02 revealed that the overwhelming focus of these plans was on recruitment rather than retention, and that the main target group comprised lower socio-economic groups. The lack of attention given to retention was almost certainly disadvantageous to minority ethnic students who were more likely than White students to be admitted but less likely to be successful.

Only two out of twelve schools mentioned race or ethnicity. The School of Education identified a specific target for recruitment of students from minority ethnic groups, while the School of Health indicated an intention to target minority ethnic groups through advertising in community journals. These references at least indicated an awareness of the need to take account of race. However, the first reflected the fact that the university was below its benchmark for teacher training with the target being set by an external agency, the Teacher Training agency, while the second did not specify any numerical targets.

While the implementation of the institution's widening participation strategy continued to prioritise class, more attention was given to race after the approval of the institution's race equality policy and implementation plan in July 2003. The institution's annual monitoring statement for widening access and participation for 2004-2005 doubled the targets relating to race from the one submitted a year earlier, while the proportion of schools which included in their plans ethnically targeted initiatives rose from 16.5 per cent to 50 per cent between 2001-2002 and 2003-2004.

Despite this, as the Director of Widening Participation put it to me, "If you go back to access in the 1980s, it was all about gender, you know, women into non traditional areas, [and] ethnic minorities. It wasn't really about social class at all. Now in the last five years ... it's really about social class, isn't it?” Interviews with the Chair of the EOWG and equal opportunities coordinator indicated that they shared the same perception.

The lack of attention to minority ethnic communities apparent in the institution's approach to widening participation was greeted with dismay by a Black member of staff: When we started widening participation, I spoke to the Head of the Widening Participation Unit (WPU) and I said to her, "Why aren't you coming to Welton to the Hindu temple [and] to the AfroCaribbean community? Why aren't you speaking to the community leaders there? There's a lot of Black males. You need to get them back into education if you're wanting participation”. And I said, you know, "These are the communities that you should be engaging in”. And she said to me, basically I don't know how to speak to these communities. I'm White and middle class. How do I speak to this community? And I said, "Well, that's your job; this is why you took the job on” ... I mean, shouldn't we employ seasonal workers to go out ... who can 
speak the language and dialogue with the Bangladeshi community ... When I spoke to [the head of the WPU], she said, Oh, you know the students we are going to concentrate on are from Corling. [They] are predominantly White. But there are other communities in Midshire that you can target. That's not been happening, you know. So are we saying you are just targeting the White community who suffer from low socioeconomic backgrounds or are we saying, you're being all inclusive ... [If you're only doing the former], that's not equality; that's not inclusion.

\section{Equal Opportunities and Human Resources}

The VC inaugurated the academic year, 2000-2001 by identifying twelve priorities in his annual statement to staff. These included a "reassessment of Human Resources policies and practices" and two relating to equal opportunities: "a review of gender issues in relation to staffing" and "the better presentation and promotion of our achievements with respect to disabilities" (Midshire University, 2000e). It is noticeable that no reference was made to race, presumably because it was assumed that this had been prioritised in the previous academic year.

The VC's prioritisation of human resources anticipated the announcement by the government later in the year of additional monies becoming available to recruit, reward and develop staff, and modernise HR management. This announcement promised to facilitate an agenda concerned with equality and diversity issues since equal opportunities was one of the priority areas identified by HEFCE in March 2001 for inclusion in institutional HR strategies. Unfortunately there were financial difficulties in the academic years 2000-2001 and 2001-2002. The university failed to meet its recruitment targets in 2000-01 and, with claw-back threatened by the funding council, staff in certain areas were declared "at risk of redundancy". In this context, all new appointments were frozen. This meant that the equal opportunities coordinator, who had left the previous term, was not replaced, and instead the Director of HR was handed responsibility for EO. Since the primary concern of HR was dealing with fall out from the financial position of the university, equal opportunities received little attention, especially in 2000-2001. This particularly applied to race where the only two targeted initiatives were not effectively implemented. The decision of EOWG to have promotional material translated into different languages was not followed through and fewer minority ethnic students were recruited to the mentoring scheme (Midshire University, 2000a, 2001a, 2002a).

The emerging HR strategy was received by EOWG at its meeting in June 2001 (Midshire University, 2001a). The strategy had three components: a resourcing strategy; a reward strategy; and a development and involvement strategy. The resourcing strategy included two equal opportunities objectives: "review and refine MU's policy and practice in relation to Equal Opportunities" and "audit MU in relation to Equal Opportunities practice as a precursor to the identification of substantial change projects to promote Equal Opportunities at MU”. In addition, the reward strategy identified a series of objectives relating to equal pay for work of equal value. Although the objectives relating to equal opportunities were very vague and there was no explicit reference to race, there was at least an acknowledgement that there was a need to establish "baseline data" in the first year of the strategy "from which targets could be developed" in subsequent years (Midshire University, 2001c).

In 2001-2002, some of the additional monies from the $\mathrm{R}$ and DS initiative were used to prevent staff in certain areas from being made redundant. The equal opportunities coordinator was not replaced but instead two White male academic members of staff were partially redeployed for a year to lead projects in equal opportunities. Both were redeployed for 0.5 of their time, on staff and student related EO projects, respectively. The first was given responsibility for commissioning an audit of EO at the university by the ECU and providing baseline and comparator data relating to EO and staffing, while the second was given responsibility for managing the mentoring scheme and providing baseline and comparator data relating to EO and students. The Director of HR announced at the October meeting of EOWG that the two staff "would be seconded jointly to undertake the role of equal opportunities coordinator in order to progress appropriate aspects of the HR strategy" (Midshire University, 2001a).

Although she tried to involve the two staff in what she saw as a shared agenda, both felt distant from what they saw as administrative work and neither attended any of the EOWG meetings. As one said, "It was the pistol to the head. I volunteered for the role as part of a redeployment package. The brief was very vague, with no specific title and a fairly rough set of objectives. It was a pretty amorphous type of project”. The projects entailed above all the production of baseline and comparator data, but unfortunately neither of them was proficient in statistical analysis. As one said: For me, as someone not trained in social science research, I found it quite time consuming ... masses and masses of data to look through which was not particularly to me, to the untrained eye, very revealing ... After a while, I began to spin on it and had to throw a lot of data to one side. The hardest thing was ... to make the data understandable in broad terms.

At face value, the academic year, 2001-2002 witnessed some developments in equal opportunities:

- At its October 2001 meeting, EOWG agreed "to convene a subgroup to undertake a review of the Equal Opportunities Policy Statement and the Working Group's terms of reference” (Midshire University, 2001a). This culminated in the production of a new equal opportunities policy that was sent out for feedback from staff and students in April 2002.

- At its January 2002 meeting, an academic presented a paper to EOWG which analysed monitoring data on staff appointments collected by the university over four years from 1997-2000 (Midshire University, 2001d). This indicated that Black applicants are less likely to be short-listed and also (though to a lesser extent) less likely to be appointed than White applicants. The same is true, though in a less marked manner, of Asian applicants.

- At the EOWG meeting in January 2002, the Director of HR "confirmed that ... the findings would [feed into] the review work of her department with regard to MU's policy and recruitment practices" (Midshire University, 2002a). The paper was subsequently taken to SET and included in a handout on Trends and issues emerging from analysis of equal opportunities recruitment and selection data, 1997-2000 (Midshire University, 2002c). SET agreed that "more analysis [was] required” (Midshire University, 2002d).

- A staff attitudes survey, with some questions on equal opportunities, was completed in May 2002 (Midshire Univer- 
sity, 2002e) and its results presented to EOWG at its June meeting (Midshire University, 2002a).

- The papers by the staff seconded to work on staff (Midshire University, 2002f) and student related (Midshire University, 2002g) aspects of EO were completed in June and sent to the Director of HR.

On closer examination, the above developments turned out to be less impressive than they sounded in the summary of progress for equal opportunities projects in the full HR strategy produced at the end of May 2002: The full human resources strategy stated that "extensive consultation had taken place on MU's new Equal Opportunities Policy” and that "approaching 100 people actively contributed during the exercise from a diverse range of backgrounds" (Midshire University, 2002b): What failed to be mentioned, however, was the fact that the original intention had also been to review EOWG's terms of reference and, more importantly, that the consultation had been about a policy statement rather than a policy, and that the statement was never in fact approved.

- The full human resources strategy stated that the university had "commissioned detailed analysis of all its equal opportunities recruitment monitoring data for the past four years and [had] identified issues and action planned accordingly" (Midshire University, 2002b). While this was partially true, the results were misrepresented to SET where it was stated that that there is evidence that applicants from ethnic minorities [were] more likely to be short listed for interview, though "less likely to be successful at the selection for appointment stage" (Midshire University, 2002c). While the formal procedures for short listing and interviewing were subsequently tightened, the only ethnically targeted initiative did not flow from the analysis of monitoring data or from the handout given to SET. The latter pointed out that "MU attract[ed] a good proportion of applicants from ethnic minority groups (17.6 per cent of the applicant pool compared to 6.7 per cent within the UK population overall)”. Despite this, the one targeted initiative was to "activate a programme of job advertisement experimentation, including use of the ethnic minority press to reach a wider pool of applicants for its posts” (Midshire University, 2002b).

- The full human resources strategy pointed out that "MU [had] undertaken its first Staff Attitudes Survey for all staff ... and targets set for a repeat survey in 12 months time, to inform future planning” (Midshire University, 2002b). This was true, but unfortunately there were very few questions relating to equal opportunities and these were not repeated in subsequent years to enable trends to be identified. While in 2002, 85 per cent of staff said they were familiar with the institution's equal opportunities policy, only 41.3 per cent agreed with the statement, "There is genuine equality of opportunity at MU” (Midshire University, 2002e). The following year, there was no question on staff awareness of policy and the closest question to the one on perceptions was one which asked respondents to agree or disagree with the statement, "There is no discrimination at MU”. A similar proportion (40\%) felt that there was no discrimination in 2003 to the proportion that the previous year felt that there was genuine equality of opportunity.

- The full human resources strategy reported that the university had "commissioned a project to determine its staff related baseline data ... and that this [had] informed target setting in EO terms" and that it had "commissioned a project to review MU's student baseline data in terms of Equal Opportunities to inform target setting also". The papers produced by the two seconded members of staff on secondment were indeed completed. However, they only reached the Director of HR in June 2002, after the full human resources strategy had been sent to HEFCE. Neither paper was presented to EOWG or any other university forum, and the author of one of the papers never even received an acknowledgement that his paper had been received. The Deputy Director of HR, who temporarily took over responsibility for HR when the Director resigned in February, indicated less than a year later that she knew nothing about these papers and could not locate them. As for the papers themselves, they made some interesting observations, but they did not produce systematic baseline and comparator data. This was acknowledged in April 2003 when the Deputy Director and newly appointed Director of HR confirmed that the staff profile data was out of date and was especially poor in relation to ethnicity where there were far too many unknowns.

- Finally, the full human resources strategy indicated that the university had commissioned the Equality Challenge Unit to conduct an EO audit at MU in September 2003. This never happened.

The section on equal opportunities in the full human resources strategy document outlining plans for 2002-2003 and 2003-2004 remained very vague, with the only specific one relating to job evaluation. The plans included "implementation of MU's revised policies in respect of equal opportunities as a whole"; harnessing "the outcome of its comprehensive review and consultation exercise on the wording and scope of its Equal Opportunities policy ...combined with the outcomes of audit by the Equality Challenge Unit to address ... staff and student perceptions of EO"; "target setting and action planning to enable MU to make significant progress" towards ensuring "its staff profile ... reflects [that of] student communities"; "to ensure equal pay for work of equal value”; to implement job evaluation using the Higher Education Role Analysis system (HERA); and to "continue to experiment with advertisement of posts in ethnic minority publications". While the review of the institution's equal opportunities policy(sic) was linked in the document to the requirement of the Race Relations Amendment Act, the only ethnically targeted initiative related to advertising in community journals.

By September 2002, the Director of HR recognised that specialist staff were required in relation to equality and diversity. Together with the Director of WP, she presented a case to the Directorate for two equality and diversity officers. This was turned down on the grounds that the income streams (R and DS and the WP premium) were not guaranteed to last. By this time, the Director of HR felt completely ground down and she resigned from her post in January 2003 (Midshire University, 2003a). Her tenure was an extremely difficult one, especially given the financial difficulties facing the university, the demands to modernise HR and the requirements to respond to new legislation. In many ways, this period was one when, following a period of treading water in addressing race equality, the institution began to sink.

\section{Race Relations Legislation}

Although the deadline (31 May 2002) was the same for the submission of the full human resources strategy to HEFCE and 
he publication of the institution's race equality policy and implementation plan (a requirement under the Race Relations Amendment Act 2000), the preparations at Midshire University for the latter started much later. The first mention of the RRAA requirements was in January, 2002 at a meeting of EOWG. At this meeting, the Director of HR announced that "the Race Relations Amendment Act Steering Group would be established in connection with the implementation of the RRA at Midshire University with a view to contributing specifically to the strands that focus on students" (Midshire University, 2002a). This group never met and the Director of HR's attempts to involve EOWG members and in particular the two seconded members of staff in the development of the university's race equality policy fell on barren ground. She did not line manage these staff who were therefore able to ignore, for example, requests to attend pertinent conferences with impunity.

The university was reminded by the Equality Challenge Unit of the deadline for the production of a race equality policy and implementation plan in February and in the same month received initial guidance from the ECU and CRE on what was required. EOWG met in March but remarkably there were no agenda items on the RRAA (Midshire University, 2002a). The first stab at developing a new policy and plan was undertaken single handedly by the Director of HR in a paper for the Governance and Employment Committee of the Governing Council. The paper asked the Governors "to endorse the proposed new policy statement ... and the proposed action plan for consultation [and] to note [their] responsibilities enshrined in the legislation [as] Governors" (Midshire University, 2002h). The paper recognised that there were resource implications and indicated (misleadingly) that "two additional posts, already planned, will underpin fulfilment of these responsibilities" (emphasis in original).

The emphasis in the paper was on consultation, with the first two appendices containing the proposed policy statement to be sent out for consultation and the proposed approach to consultation. In addition, two further appendices drew attention to the wide range of policy items that needed to be reviewed and a proposed schedule for fulfilling the requirements of the legislation. The paper did indicate an understanding of the legislation, with the proposed new equal opportunities policy statement translating the general and specific duties relating to race into general and specific duties relating to all strands of equality. The proposed statement contained three paragraphs with the first paragraph relating to the general duties enshrined in the legislation, and the second and third paragraphs relating to some of the specific duties in italics. It is sufficient here to quote the first paragraph in order to give a flavour of the proposed policy statement: "Midshire University (MU) recognises and values its role in a diverse society and is opposed to, and will positively address, all forms of unfair discrimination, on whatever grounds. MU will promote equality of opportunity and good relations between people” (Midshire University, 2002h).

What is evident is the way that race was subsumed under a more general equal opportunities agenda. This is evident throughout the paper, including the exceptional moments when there was explicit reference to race. The proposed schedule for example identified two issues that needed to be addressed before 31 May: to "prepare and plan to maintain a written statement of MU's race equality policy for promoting race equality as part of its overall Equal Opportunities policy" and to "de- velop and secure agreement to an action plan to meet MU's duties to eliminate unlawful discrimination; promote equality of opportunity; [and] promote good relations between people of different racial groups, as part of its overall Equal Opportunities action plan” (Midshire University, 2002h).

Leaving aside the misleading section on resource implications (the proposal to have any posts in equality and diversity was consistently rejected by the Directorate as unnecessary and unaffordable before 2003), what was most remarkable about the paper was the lack of explicit reference to race and the insistence, when reference was made to race, on placing it under a broader agenda. This tendency was even more apparent in the university news briefing at the beginning of May 2002 in the section headed, Equal Opportunities Policy and Initiatives Relating to Race Relations (Midshire University, 2002i). The item, which included the draft policy statement on equal opportunities, stated: The Governor's Governance and Employment Sub Committee endorsed the draft policy, consultation plan and draft implementation plan ... This policy will be inclusive of MU's race equality policy and plan for promoting race equality. We are now seeking to get feedback on the policy from staff and students. Interestingly, the policy statement was now a fully fledged "policy" and the schedule of what needed to be done was now an "implementation plan" (my emphasis).

The first paragraph of the three paragraph policy had changed marginally since the meeting of the Governing Council's Governance and Employment Committee. It now read: "Midshire University (MU) recognises and values its role in a diverse society and is opposed to, and will tackle, all forms of unfair discrimination, on whatever grounds. MU will promote equality of opportunity and good relations between all people of diverse backgrounds” (Midshire University, 2002i). It should be noted, however, that the policy, though supposedly inclusive of race, still refused to make any reference to race or address any specificities relating to this strand of (in)equality. This was surprising because by this stage, the Director of HR had been briefed by colleagues who had attended the ECU/CRE conference in April on "meeting the deadline".

No progress was made on the institution's race equality policy and implementation plan before the end of May. While the submission of a full human resources strategy to HEFCE met the 31 May deadline, the only written race equality policy available at that time comprised the above new equal opportunities policy statement. The EOWG met in June 2002 (Midshire University, 2002a). The agenda again remarkably did not include an item on the RRAA and, even more remarkably, the VC's annual address to the group expressly mentioned gender and disability, but remained resoundingly silent over race. Nonetheless an item entitled, EO Performance Indicators and Targets, related to a report by the Director of HR "on equal opportunities policy and practice impact assessment and targets for improvement 2002-2005” (Midshire University, 2002j).

This paper drew heavily on the section in the full human resources strategy on equal opportunities, but it did include for the first time some key performance targets that had been informed by the limited baseline data available. While five of these did not relate to ethnicity, three did. The baseline data indicated that "staff from ethnic minorities" comprised 2.8 per cent of the total (when in the county, minority ethnic communities comprised 3.5\%); that the "per cent of senior salaried staff from ethnic minorities" comprised 2.9 per cent (one person in fact); and that the "per cent of academic staff from ethnic mi- 
norities" was unknown. This data informed the targets for 2003, 2004 and 2005: "per cent staff from ethnic minorities 4 per cent, 5 per cent, 6 per cent [UK benchmark 11\%] ... per cent senior salaried staff from ethnic minorities 4 per cent, 5 per cent, 6 per cent [UK benchmark 11\%] [and] per cent academic staff from ethnic minorities 10 per cent, 11 per cent, 12 per cent [UK benchmark 11\%]". In addition under a heading entitled, "KPIRace Relations Impact Assessment”, the paper briefly summarised the evidence presented (inaccurately) to SET (Midshire University, 2002c) on ratios relating to staff recruitment and selection by ethnicity and gender, and identified targets. Those relating to ethnicity were as follows: "ratio of per cent applicants from ethnic minorities in applicant pool: ratio of ethnic minorities within economically active UK population-equal to or greater than 1:1; ratio of per cent applicants from ethnic minorities in applicant pool: short listed pool-equal to or greater than $1: 1$; ratio of per cent applicants from ethnic minorities in short listed pool: appointed pool equal to or greater than 1:1" (Midshire University, 2002j).

The EOWG met again in October, but there was still no agenda item on the RRAA and no further progress was reported (Midshire University, 2002a). In the same month, HEFCE indicated that it wished the university, like other HEIs, to submit its race equality policy and implementation plan to the council by November 1, 2002 so that it could fulfil its monitoring remit under its own race equality scheme. Midshire University duly obliged and forwarded its response with an accompanying letter from the Pro VC which pointed out that "to date we have held extensive consultation and dissemination on reviewing and revising our policy, have carried out impact assessments, and have detailed the further action to be taken”. The document was entitled revealingly, Equal Opportunities at $M U$ and contained five sections [the "draft new policy statement"; an "overall action plan"; "impact assessment 2002 (Staff related)"; "Targets 2002-2005 (Staff related)”; "Detailed monitoring-key performance indicators (Staff related)"] and an appendix containing the "existing equal opportunities policy" (Midshire University, 2002k).

The new policy statement was the three paragraphs on equal opportunities discussed above. The only reference to race was in the second paragraph which stated, "Inductively this policy refers to opportunities for career advancement, staff development and training, as well as fairness in student admission, assessment, progression, and access to support services. It incorporates MU's Race Relations Policy” (emphasis in original). The overall action plan was an equal opportunities action plan (just over a page) which made only one reference to race, notably to "develop a strategy on race promotion". The other three sections were exclusively related to staff. The one on impact assessment (two pages) summarised some data relating to the staff profile, the analysis of the monitoring data on the recruitment of staff over a four year period and the staff attitudes survey. In each case, the summary focused on equal opportunities rather than race specifically. The one (one page) on targets reproduced the key performance targets identified earlier in the paper presented at the June meeting of EOWG, while the one on detailed monitoring (two pages) cut and pasted a section of the full human resources strategy relating to equal opportunities with the remaining part of the section on KPIs in the paper presented to EOWG in June. In both cases, race was subsumed within an equal opportunities agenda and, while race was mentioned in these sections, this was alongside other strands of (in)equality.

The document submitted to HEFCE did not indicate that Midshire University had taken on board the guidance produced by ECU and the CRE. The document was about equal opportunities and not race and did not demonstrate how its policy and implementation plan addressed the general duty or the specific duties enshrined in the legislation. It completely ignored the specific duties relating to students and only made tangential reference to matters pertaining to the specific duties relating to staff.

The Vice Chancellor heard back from the ECU on 12 February 2003 (Midshire University, 2003b) and a week later from HEFCE on 20 February 2003 (Midshire University, 2003c). The ECU reported that Midshire University was "considered not to be aligned with the requirements of the Race Relations (Amendment) Act, and that in consequence the whole approach need[ed] urgent revision” (Midshire University, 2003b). The race equality policy analysis of the university's document was completely damning: "Midshire University has not submitted a Race Equality policy or any other document for satisfying the requirements of the legislation”. Judged against a template of 26 items, MU was identified as wholly failing to fulfil its obligations on 24 and only partially fulfilling them on the other two (Midshire University, 2003b). The follow up letter from HEFCE "reiterated the risk that non-compliance with the RRAA brings", given "the Commission for Racial Equality's new enforcement powers” (Midshire University, 2003c). Accordingly, the university was asked to resubmit a revised policy and plan by the end of May, 2003.

\section{Explaining Failure}

The author of the document left the university a couple of weeks before the university heard that its policy and plan were unsatisfactory. She was therefore an easy scapegoat who could be blamed with impunity for this failure. And this was a common response. Asked why the university had received the lowest grade, one Pro Vice Chancellor was adamant: "It was Y's fault. The problem was that nobody could manage her and she created obfuscation by quoting employment law. She reassured the Governors but in retrospect they should have followed matters up. [The senior PVC] now regrets sending the stuff off to HEFCE". The Chair of EOWG was more graphic: "Y cocked things up and didn't bother to let EOWG know what she was doing".

The Director of WP agreed that the Director of HR was to blame but expressed more sympathy towards her. Asked why the university failed to get it right, she said: "It was Y, you know. It's the way she worked. She just wasn't somebody who worked well with other people ... She was so overloaded that when it came to it she had to produce something ... There seemed to be lots of cases of staff who were kind of making complaints against other members of and HR having to get involved. I can't remember, but it was kind of thirty, forty individual cases. I mean, it was amazing. You wouldn't have believed it. I remember at one point Y produced this kind of paper of all the ongoing work, and it was huge. But it did range from very, very serious big things, you know, through to more trivial... At the end of the day there was nobody at Directorate level saying. This matters, we must get this right, and pass other stuff down the line".

While the response of senior staff was to blame the Director 


\section{A. PILKINGTON}

of HR for the university's ignominious failure, there is some recognition in the quotations above that an individualistic explanation is insufficient. The PVC referred to the Governors, and it was the governing body that signed off the policy and plan "that so patently fail[ed] to satisfy the requirements of the legislation” (John, 2003: p. 5). The Chair of EOWG referred to EOWG, and it was indeed the case that this body lacked sufficient authority or expertise to challenge the Director of HR. The Director of WP referred to the Directorate, and it was indeed the case that the Director of HR was not effectively managed or supported by her line manager. Unfortunately, the PVC who was her line manager became seriously ill in January 2003 and never returned to work. Although an Acting PVC and later a newly appointed PVC took over line management responsibilities, the Director of HR was not given the requisite help at Directorate level to identify priorities. One writer has argued that "the [race equality] documents were produced by individuals in situations of extreme pressure" (Ahmed, 2007: p. 592). If this was true across the sector, it was particularly true at Midshire.

It is helpful to do a thought experiment. As one commentator points out, "Few, if any, governing bodies would adopt a 'take it or leave it' attitude to health and safety legislation, public indemnity insurance legislation or, increasingly these days, sexual harassment legislation” (John, 2003: p. 5). As for the Directorate and Senior Executive Team (SET), it is unlikely that such a hands off approach would have been taken towards issues relating to quality assurance, given an impending institutional review from the QAA. In fact, great care was taken to ensure that the illness of the PVC's did not impact on quality assurance. It seems evident that, for both the governing body and senior management, the development of a race equality policy and action plan was not considered a priority.

It is difficult not to conclude that an adequate explanation for the failure of the university to develop a satisfactory race equality policy and implementation plan must therefore move beyond the level of the individual and even the level of governance arrangements to that of the institution as a whole. We saw earlier, in the university's response to previous initiatives, that there was reluctance at the university to address race issues. The failure to produce an appropriate race equality policy and plan was thus the latest example of a knee jerk reaction to subsume race under another agenda and thus to deprioritise race equality. Midshire University is unlikely to be the only university to do this. For, as I have argued elsewhere, universities in the UK are typically characterised by the "sheer weight of whiteness" which blinds senior managers and academics to racial inequalities in their midst (Pilkington, 2013).

\section{REFERENCES}

Ahmed, S. (2007). You end up doing the document rather than doing the doing: Diversity, race equality and the politics of documentation. Ethnic and Racial Studies, 30, 590-609. doi: $10.1080 / 01419870701356015$

Carter, J., Fenton, J., \& Modood, T. (1999). Ethnicity and employment in higher education. London: Policy Studies Institute.

John, G. (2003). Review of race equality policies and action plans in HEFCE-funded Higher Education Institutions. www.gusjohn.com/wp-content/uploads

Midshire University (1999a). Equal opportunities working group minutes. University Documents, February, May, December.

Midshire University (1999b). Racial equality: Leadership challenge.
September.

Midshire University (2000a). Equal opportunities working group minutes. University Documents, February, June, October, December.

Midshire University (2000b). Millennium Commitment from the vice chancellor. University Document, January.

Midshire University (2000c). Audit of current practice in the university. University Document, January.

Midshire University (2000d). Is MU characterised by institutional racism? University Document, April.

Midshire University (2000e). Vice chancellor's annual statement. University Document, September.

Midshire University (2001a). Equal opportunities working group minutes. University Document, March, June, October.

Midshire University (2001b). Midshire University strategy for widening participation. University Document, July.

Midshire University (2001c). Emergent human resources strategy 2001-2004. University Document.

Midshire University (2001d). Recruitment report, 1997-2000. University Document.

Midshire University (2002a). Equal opportunities working group minutes. University Document, January, March, June, October.

Midshire University (2002b). Full Human Resources Strategy. University Document.

Midshire University (2002c). Trends and issues emerging from analysis of equal opportunities. Recruitment and selection data for 1997 2000. University Document.

Midshire University (2002d). Senior executive team minutes. University Document, January.

Midshire University (2002e). Staff attitude survey results. University Document, June.

Midshire University (2002f). Staff equal opportunities at MU. University Document.

Midshire University (2002g). Equal opportunities and the student population at MU. University Document.

Midshire University (2002h). Equal opportunities policy and practice at MU and the implications of the race relations amendment act specifically. University Document, April.

Midshire University (2002i). Equal opportunities policy and initiatives relating to race relations. University News Brief, University Document, May.

Midshire University (2002j). Report on equal opportunities policy and practice impact assessment and targets for improvement, 2002-2005. University Document, June.

Midshire University (2002k). Equal opportunities at MU. University Document, October.

Midshire University (2003a). Equal opportunities working group minutes. University Document, January.

Midshire University (2003b). Evaluation of race equality policies and action plans. University Document, February.

Midshire University (2003c). Race equality policies evaluation. University Document.

Pilkington, A. (2011a). Institutional racism in the academy. Stoke on Trent: Trentham Books.

Pilkington, A. (2011). Business as usual: Racial inequality in the academy ten years after macpherson. In K. Hylton, A. Pilkington, P. Warmington, \& S. Housee (Eds.), Atlantic crossings: International dialogues on critical race theory (pp. 93-114). Birmingham: Higher Education Academy.

Pilkington, A. (2013). The sheer weight of whiteness of the academy: A UK case study. In R. Race, \& V. Lander (Eds.), Advancing race and ethnicity within education. Basinghurst: Palgrave. 